\title{
LETTER TO THE EDITOR \\ History of cervical spine surgery: from nihilism to advanced reconstructive surgery
}

\author{
Spinal Cord (2014) 52, 339; doi:10.1038/sc.2014.14; published online 18 February 2014
}

Surgery on the spine is controversial, even to the present day, so a history of the subject is to be welcomed to understand how the practice has evolved. The article aims to provide an accessible overview to a large audience of non-surgical spinal cord injury experts. ${ }^{1}$ Unfortunately, there are blemishes that should be corrected. There are errors of omission and there are errors of commission.

The authors acknowledge the work of Guy de Chauliac and Vesalius but they have not acknowledged that the work started with Ambroise Paré, the premier surgeon of the 16th century who in his textbook of surgery recommended laminectomy when the spinal cord was compressed. ${ }^{2}$ Contrary to Paul of Aegina, he recommended that the fractured spinous process should not be removed if it was still attached to the periosteum. He described and illustrated methods of reducing the dislocated spine, advising initial manual reduction and then the use of pieces of wood to achieve a more satisfactory reduction. Fabricius Ab Aquapendente suggested open reduction of fracture dislocation of the spine, pointing out the practical difficulties of intractable haemorrhage that could be arrested by the use of twisted oakums, which would suggest that he did operate on the spine. $^{2}$

In the 19th century, Astley Cooper, the doyen of British surgeons, a popular teacher and author of many textbooks, was very interested in the management of spinal injuries. In 1824, he described how a violent blow to the loins could produce paralysis of the lower extremities. He gave an account of how Mr Henry Cline, whom he was living with as a pupil, carried out a laminectomy. Cline was a surgeon and professor, and eventually became President of the Royal College of Surgeons. Being an excellent anatomist and a most reasonable surgeon, Cline saw no reason why cases of this kind should not be treated in the same way as a depressed fracture of the skull. Mr Frederick Tyrell had attempted the operation after Cline but both cases terminated unfavourably. ${ }^{2}$

Cooper was a distinguished man, perhaps the best teacher in London. Unfortunately, Cooper's observations of the physical signs and prognosis in paraplegia were lost sight of because of his views on treatment by laminectomy. He denigrated anyone who opposed him and this led to the celebrated controversy with Sir Charles Bell. Bell recommended conservative treatment and Cooper recommended surgery. Bell believed that the damage to the spinal cord was done at the time of injury and he wrote a textbook on the subject. Bell's views received wide acceptance in Britain. ${ }^{2}$ These operations and the controversy that ensued received widespread acknowledgement at the time and such was the prestige of the protagonists that it influenced treatment until the 20th century; therefore, it was not AG Smith in 1829 who performed the first laminectomy, and the previous work should be acknowledged.

The authors say that the procedure to stabilise the cervical spine was mainly performed using a posterior approach and they quote Holdsworth and Hardy's work in 1953. I knew Alan Hardy very well and for many years. I consulted with him and he worked as a locum for a short while after his retirement at Stoke Mandeville Hospital. I remember well the controversies between Sir Ludwig Guttmann and Holdsworth during spinal meetings at Stoke Mandeville when they battled about the appropriateness of surgery upon the spine. The authors say that in 1953, Holdsworth and Hardy reported better results by using interspinous wiring and grafting. This is not correct. The paper refers to the early treatment of fractures of the thoracolumbar spine and 68 patients with fracture-dislocations of the thoracic spine of whom 47 were treated from the beginning. They describe manipulation and reduction of the fractures followed by fixation of the fracture by means of two plates bolted to the spinous processes above and below the level of the fracture. There is no mention of the treatment of cervical fractures or bone grafting. I hope these corrections are helpful.

\section{CONFLICT OF INTEREST}

The author declares no conflict of interest.

J Silver

Institute of Sports Medicine, Wendover, UK E-mail: jrussellsilver@btconnect.com

\footnotetext{
1 Dweik A, Van den Brande E, Kossmann T, Mass AIR. History of cervical spine surgery: from nihilism to advanced reconstructive surgery. Spinal Cord 2013; 51: 809-814.

2 Silver JR. History of the Treatment of Spinal Injuries. Kluwer Academic/Plenum Publishing: New York, NY, USA 5-16, 2003.
} 